\title{
The Clean Development Mechanism: How to Increase Benefits for Developing Countries
}

\section{John Humphrey*}

\section{Introduction}

The Clean Development Mechanism (CDM) was established by Article 12 of the Kyoto Protocol. The Protocol sets a series of targets for the reduction of emissions of greenhouse gases ${ }^{1}$ (GHG) for so-called Annex 1 countries, i.e. the (industrialised) countries that have emissions targets under the United Nations Framework Convention on Climate Change (UNFCCC). The targets can be achieved not only through reducing emissions in the home country but also through obtaining "Kyoto units", denominated in tons of $\mathrm{CO}_{2}$ equivalent $\left(\mathrm{tCO}_{2}-\mathrm{e}\right)$. There are various mechanisms that allow countries to meet their target requirements by obtaining Kyoto units arising from emissions reductions made in other countries (see Yamin, this Bulletin, for an overview of the climate regime). One of these mechanisms is the CDM, which is specifically designed to promote GHG reduction projects in developing countries. It has been summarised as follows:

An investor from an industrialised country or an industrialised country government, can invest in, or provide finance for, a project in a developing country that reduces greenhouse gas emissions so that they are lower than what would have been without the extra investment -i.e. compared to what would have happened without the CDM under a business as usual outcome. The investment then gets credits - carbon credits for the reductions and can use these credits to meet their Kyoto target. (CDMWatch 2003: 8)

Investments in projects that are approved and certified as providing additional reductions of GHG emissions generate certificates of emission reduction
(CERs), which can be used by Annex 1 countries as a contribution to meeting their emission reduction targets. The scheme is intended to benefit the Annex 1 Parties by allowing them to find the most cost-effective projects for reducing greenhouse gas emissions, even if these are not located within the Annex 1 countries. The scheme is intended to attract private sector involvement, either through investment aimed at generating saleable CERs, or through the purchase of these CERs by companies that have their own emissions obligations. ${ }^{2}$

At the same time, the scheme is intended to provide specific benefits for developing countries by, first, involving them in emissions reduction activities and, second, promoting sustainable development. For the host (developing) countries, the CDM is expected to provide some of the following: transfer of clean technology, foreign direct investment in emission reduction projects, localised environmental improvement and an income stream from the sale of CERs. The precise benefits will vary from project to project, but the mechanism is specifically set up with development objectives in mind and host country governments have to confirm the development effects of proposed projects.

The development of the CDM is at an early stage and although various projects have been put forward for appraisal, none has been formally registered or implemented. At the same time, there are considerable uncertainties about how the mechanism will operate in practice and what will happen after the end of the first commitment period under the Kyoto protocol in 2012. In this context, analysis of the CDM and its impact on developing countries have been focused on issues such as the 
level of likely investment in CDM projects, the supply and demand factors that will influence the market price of a unit of emissions reduction (usually measured as tons of $\mathrm{CO}_{2}$ equivalent per annum, $\mathrm{tCO}_{2}-\mathrm{e}$ ) and the developmental impact of different types of CDM project (particularly contrasting the difference between renewable energy projects, fuel switching projects and methane/fluorine gas reduction projects). ${ }^{3}$ There has also been considerable discussion of the questions of establishing baseline emission levels and additionality so that CERs arise from genuine reductions in GHGs.

This article focuses on the development question and in particular how market structures can impact on the level of benefits to developing countries from the CDM. It analyses this question from the perspective of global value chains. This pays particular attention to the way in which sequences of activities are bundled within enterprise boundaries, or split across them and the different ways in which activities are coordinated across firm boundaries. In particular, it draws attention to the different ways in which inter-firm coordination takes place within the global economy, going beyond the dichotomy between the vertically integrated firms and arm's-length market relationships and also emphasising the importance of institutions and standards in structuring inter-firm relationships. ${ }^{4}$

The benefits to developing countries will depend not only on the overall level of investments, but also on the nature of the projects and the extent to which they generate spillovers and learning in developing countries. These will be affected by the market structures that arise in response to the CDM and its governance requirements.

\section{Projects and project governance in the CDM}

The CDM can be characterised as a sequence of economic activities - projects and the economic benefits that flow from them - and a set of governance procedures that define what projects are suitable for the CDM and then validate, register and monitor their operation prior to the emission of tradeable CERs.

The economic activities can be split into four stages:

1. The design of CDM projects in developing countries.
2. The implementation of these projects, resulting in investment and technology transfer to developing countries.

3. The operation of these projects, reducing greenhouse gas emissions and leading to the emission of CERs.

4. The sale and trade of CERs, leading to an income stream, captured by one or more of the parties to the project and a market for CERs.

At the same time, these activities are subject to governance mechanisms established by the Kyoto protocol and institutions designed to put it in practice:

1. All projects begin with a proposal set out in the project design document (PDD) which has to be approved by both the host country government through its "designated national authority" (DNA) and by the home country (originator of the investment) government, and then put out for public comment by interested parties.

2. The emissions reduction planned to arise from the project has to be validated by a "designated operational entity" (DOE1) accredited by the CDM Executive Board.

3. Registration of the project with the CDM Executive Board. The Board is responsible for establishing baselines and monitoring methodologies.

4. Monitoring and verification of actual performance of the project by a second and separate designated operational entity (DOE2). This DOE plays a similar role to accredited bodies that certified compliance with international standards such as ISO 9000.

5. Issuing of CERs by the CDM Executive Board.

These governance mechanisms are designed to ensure that projects result in genuine emissions of GHGs below that which would otherwise have occurred. They also establish transparency through mechanisms such as the publication of PDDs, requirements for public comment, and the webcasting of Executive Board meetings.

\section{Market structures issues}

The impact of the CDM will be influenced by the market structures that arise in response to the economic opportunities it creates and governance 
mechanisms that are put in place. The question of markets arises in relation not only to how CERs are traded, but also to the way projects are financed, designed, constructed, operated and certified.

\subsection{Bundling and splitting of activities}

Two of the potential benefits of the CDM are increased investment in developing countries and the transfer of clean technologies. It seems to be easily assumed that the mechanism for this would be foreign direct investment (FDI) by Annex 1 countries (see, e.g. Ellis et al. 2004: 15). Firms will make investments in projects that lead to emission reductions and in the course of creating the project (for example, a power plant using renewable fuel), technology will be transferred. Implicitly, this assumes that the investor and the technology provider are the same firm and that they may also be involved in the construction operation of the project. In fact, there is no reason to suppose this. The company owning the relevant technology may be a specialist technology company that might be hired by various contractors and/or project promoters. Similarly, the finance for the project could be separated from the construction and the operation and might not be channelled through foreign companies at all.

Such separation might be desirable. First, there is a global tendency towards the decomposition of innovation, with an increasing growth of specialist technology suppliers. The benefits to developing countries, particularly in the area of technology acquisition, might be best served by local companies working with these technology specialists. This would imply partnerships between developed and developing country firms: e.g. between clean technology specialists in developed countries and construction companies or energy companies in developing countries.

In the longer term, this could be more beneficial for developing technological capabilities in the area of clean technologies. Lall (2002: 52-3) argues strongly that while FDI transfers the results of research and development to host countries, it does not transfer the process of technology development and it does not build local capabilities so effectively. For these reasons, joint ventures with specialist technology suppliers might provide a better route to generating developing country capabilities in this field. These capabilities could be combined with local-owned, export-oriented construction businesses that exist in countries such as Brazil.

The full utilisation of these capabilities might then depend upon the growth of CDM projects involving investment financed from within an Annex 1 country or investment directly from one non-Annex 1 country to another. Far from limiting technology transfer (as suggested by Ellis et al. 2004: 11), this could stimulate the development of developing country capabilities. Suggestions for so-called "unilateral-CDM" and South/South CDM projects have been the subject of debate in the design phase of the climate negotiations. In particular, there are concerns that the development of such projects (and the revenues they generate) would undermine incentives for developing countries to assume emissions targets at some later date. As the implementation of CDM proceeds, the issue of the positive developmental impact of such projects may need to be assessed and weighed against their long-term environmental impact. The real challenge may be to find ways of safeguarding the environmental aims of the CDM while at the same time enabling developing countries to develop capabilities in this area.

\subsection{Transactions costs and intermediaries}

The transaction costs involved in the development of CDM projects take at least two forms. First, there are the costs arising from the governance mechanisms outlined above. It has been argued that these will be substantial and 'constitute a big barrier to developing CDM projects' (Ellis et al. 2004: 30). Second, there are the costs of finding projects and partners and working in new countries. What strategies will be used to reduce these costs and what will be their implications for the bundling and splitting of activities and the emergence of specialist firms?

It may well be easy to develop well-functioning markets for the outcomes of CDM projects, the tradeable CERs and here, the main challenges are to create a supply and demand for market liquidity and to remove uncertainties about the likely value of these certificates. With regard to the role of markets in bringing together the different agents involved in the development, construction and operation of projects, the challenges are different. Four problems will emerge:

1. Given the level and complexity of the inter-firm coordination required for one-off, complex projects, the range of issues generated by the 
CDM governance mechanisms and the longer time periods involved, specialist intermediaries may well emerge to facilitate and/or coordinate relationships between the different parties and with the CDM governance mechanisms. These intermediaries can gain economies of scale and learning through the development of multiple projects. They might well specialise in working with particular DOEs and governments and with the Executive Board. Given the advantage that the specialist intermediaries will have over companies working on single projects, they will be able to obtain a significant share of the rents from CDM projects. What strategies are there for promoting the growth of developing country intermediaries that can manage the system and bring together different actors effectively, ensuring an increased flow of projects and also retaining the benefits (income streams and technology acquisition) in the host countries?

2. The high fixed costs associated with complying with CDM regulations may undermine the development of small-scale projects. What can be done to reduce costs beyond the simplified procedures already in place?

3. The costs of working with host country governments, DOEs and specialist intermediaries may strongly favour the concentration of projects in a small number of countries. This concentration is already evident, with 55 per cent of the expected emissions reductions from 137 CDM projects coming from just four large developing countries (Brazil, China, India and Indonesia) (Ellis et al. 2004: 18-19). To what extent should multilateral agencies and government-funded schemes for promoting CDM projects focus on increasing the spread of projects? The World Bank's Prototype Carbon Fund (PCF), for example, allocates funds by region, as well as by type of project (de Coninck and van der Linden 2003: 9). The option of regional quotas for investment in order to ensure that the poorest countries are not excluded from the potential benefits of the CDM is suggested by Panayotou (1998: 46). Alternatively, some consideration could be given to resurrecting the "portfolio approach" to the CDM, as discussed by Yamin (1998: 54-6). This approach would have channelled investment through the CDM itself, rather than leading project development to direct relationships between the parties.
4. Finally, the transactions costs involved in developing new projects may work against the goal of additionality. It only becomes worth incurring the extra costs if much of the work for the project would have been done anyway. In effect, the revenue stream from the CERs generated only has to cover the costs of meeting the CDM governance requirements. Critiques of the projects financed by the first round of the Dutch-funded CERUPT programme argue that much of the finance is going to projects such as fuel substitution and hydroelectricity that would have taken place anyway. ${ }^{5}$ This may indicate a lack of suitable alternative projects, rather than a failure of the programme to recognise the additionality issue.

\subsection{Validation and monitoring/verification}

The role of the designated operational entities (DOEs) responsible for validation of project designs and the monitoring/verification of emissions reduction is critical in the governance of the CDM and this work is likely to generate substantial revenues. Experience with global governance in the field of quality standards, notably ISO 9000, indicates that this work is likely to be dominated by international firms who can offer a service to potential investors covering a range of countries and also provide credible certification. This tends to decrease the transaction costs of schemes by allowing companies to work with a single service provider (although local subsidiaries or franchises may carry out the work).

This work itself generates competences that can be applied more widely in the economy. Although the CDM separates the roles of validation and verification for each project, these competences will be contained within particular service providers and can be used to support capability acquisition by local firms. It is, therefore, reasonable to ask whether the procedures adopted by the CDM favour the relatively few transnational business service companies that are so important in other areas of international certification and what might be done to promote participation in this business by developing country firms. There would be direct benefits from employment in revenues generated and also greater potential spillovers to investors and operating companies in developing countries. Although the International Organisation for Standardisation (ISO) has become active in climate 
negotiations in recent years in explaining its work, many climate policy makers do not fully understand how quality standards work, particularly in developing countries.

\subsection{Orient project towards development}

Even in the initial stages of CDM project preparation, it is evident that there are trade-offs between profit maximisation by investors and the sustainable development objectives of the CDM. The latter are most likely to be achieved through projects such as renewable energy schemes and such schemes would also contribute to the financing of necessary energy infrastructure investments in developing countries (see also Leach and Leach, this Bulletin). In contrast, large potential generators of CERs, such as flurianted gases reduction projects, have no broader developmental impact, but these projects provide the lowest-cost means of generating Kyoto units.

Host country governments, in particular the governments of small countries, may have little to bargain with in this area, particularly because the global scope of the CDM means project investors have a wide choice of location. Therefore, extra means are needed to increase the developmental impact of CDM projects. The first is on the supply side. Home country governments could prioritise projects with a strong development element. This can be done through the criteria for allocating investment finance. Alternatively, there could be means of certifying investment funds as "development friendly". Second, there is a potential demand-side approach. It may be possible to differentiate, or "brand", particular types of CDM projects (or, more specifically, the CERs that they generate) as being of greater value because they have greater developmental impact. Particular companies are already doing this. However, on a project basis, this ties the increased "value" of the project to the particular investor or operator. The costs of doing this would be reduced if some form of global standard for a "fair CDM" label could be developed. While this would involve costs - the costs of developing the criteria, the costs of certifying compliance, sanctioning non-compliance and controlling the use of the standard (label, etc.) - it would be less expensive than developing private labels for each project or company. A further step in this direction would be to separate the project from the indicator of increased value by creating certificates that could be traded independently. This type of scheme is used with "green certificates" for renewable energy in Europe (Kooijman-van Dijk 2003). This would allow many different agents to support such projects by purchasing such certificates, or paying increased prices for products associated with them (and thereby giving value to the certificate) without having to be directly involved in the projects themselves.

\section{Conclusions}

Uncertainties about the entry into force and future evolution of the Kyoto Protocol are undoubtedly having a depressive effect on the level of CDM activity. But at the same time, the pace of CDM project planning is picking up as confidence grows in the interim arrangement for the CDMs, which will continue to function under the legal authority of the UNFCCC. Now that the international governance structures of the CDM are more or less settled, the coming period provides an important opportunity for a more grounded examination of the likely impacts of emergent market structures on the level of benefits to developing countries. The early phase of the CDM will be a mixture of learning and jockeying for position as countries, firms and other actors work out how to make the most of opportunities presented. Policy makers have often complained about frenetic pace and complexity of climate negotiations, particularly on the CDM. The relative lull in the international negotiations provides a timely opportunity for researchers and policy makers, particularly from developing countries, to examine some of the issues and questions raised in this article to ensure the new carbon markets generate as high a level of developmental benefits as possible for developing countries. 


\section{Notes}

* The author is particularly grateful to Farhana Yamin for stimulating the writing of this article and providing valuable support and advice on the subject matter.

1. The greenhouse gases (GHGs) covered by the protocol are carbon dioxide $\left(\mathrm{CO}_{2}\right)$, methane $\left(\mathrm{CH}_{4}\right)$, nitrous oxide $\left(\mathrm{N}_{2} \mathrm{O}\right)$, hydrofluorocarbons (HFCs), perfluorocarbons (PFCs) and sulphur hexafluoride ( $\left.\mathrm{SF}_{6}\right)$.

2. Although emissions reductions targets and obligations are placed on nation states, governments can transfer some of the onus for meeting them onto private companies. The UK government emissions trading scheme, for example, provides incentives for private

\section{References}

CDMWatch, 2004, Clean Development Mechanism (CDM): Status Note, March

CDMWatch, 2003, The Clean Development Mechanism (CDM) Toolkit, http://cdmwatch.org, accessed April 2004

de Coninck, H. and van der Linden, N., 2003, An Overview of Carbon Transactions, The Netherlands: Energy Research Centre

Ellis, J., Winkler, H. and Corfee-Morlot, J., 2004, CDM: Taking Stock And Looking Forward, Paris: OECD

Gereffi, G. and Kaplinsky, R., 2001, 'The value of value chains', IDS Bulletin, Vol 32 No 3, special issue

Haites, E., 2004, Estimating the market potential for the Clean Development Mechanism: review of models and lessons learned, Report prepared for The World Bank, International Energy Agency and International Emissions Trading Association, Toronto: Margaree Consultants Inc.

International Rivers Network, 2004, Damming the CDM, www.irn.org/programs/greenhouse/ sector companies to undertake voluntary, but legally binding Climate Change Agreements which could be met through emissions trading. (See www.defra.gov.uk/ environment/climatechange/trading/ukets.htm)

3. See, for example, Haites (2004), CDMWatch (2003) and Ellis et al. (2004).

4. For a set of papers outlining this approach, see Gereffi and Kaplinski (2001). More recent papers can be found at the website of the global value chains initiative, www.ids.ac.uk/globalvaluechains/index.html.

5. See CDMWatch (2004) and the International Rivers Network (2004).

index.asp?id=/programs/greenhouse/021025.da mmingthecdmpr.html, accessed April 2004

Kooijman-van Dijk, A., 2003, 'Renewable energy policy in Europe', GrIPP-Net News, Vol 2 No 4, www.asem-greenippnetwork.net/documents/ tobedownloaded/grippnetnews_0204.pdf (accessed April 2004)

Lall, S., 2002, 'Linking FDI and technology development for capacity building and strategic competitiveness', Transnational Corporations, Vol 11 No 3: 39-88

Panayotou, T., 1998, 'Six Questions of Design and Governance', in J. Goldemberg (ed.), Issues And Options: The Clean Development Mechanism, New York: UNDP: 45-52

Yamin, F., 1998, 'Operational and Institutional Challenges Six Questions of Design and Governance', in J. Goldemberg (ed.), Issues And Options: The Clean Development Mechanism, New York: UNDP: 53-80 